\title{
The Other Drug War: Societal Attitudes and the Pharmacologic Treatment of Anxiety Disorders
}

\author{
Bruce Wenokur, D.O., M.P.H. \\ Detroit Psychiatric Institute, Detroit, Michigan
}

Follow this and additional works at: https://jdc.jefferson.edu/jeffjpsychiatry

Part of the Psychiatry Commons

Let us know how access to this document benefits you

\author{
Recommended Citation \\ Wenokur, D.O., M.P.H., Bruce (1993) "The Other Drug War: Societal Attitudes and the Pharmacologic \\ Treatment of Anxiety Disorders," Jefferson Journal of Psychiatry. Vol. 11 : Iss. 1 , Article 5. \\ DOI: https://doi.org/10.29046/JJP.011.1.002 \\ Available at: https://jdc.jefferson.edu/jeffjpsychiatry/vol11/iss1/5
}

This Article is brought to you for free and open access by the Jefferson Digital Commons. The Jefferson Digital Commons is a service of Thomas Jefferson University's Center for Teaching and Learning (CTL). The Commons is a showcase for Jefferson books and journals, peer-reviewed scholarly publications, unique historical collections from the University archives, and teaching tools. The Jefferson Digital Commons allows researchers and interested readers anywhere in the world to learn about and keep up to date with Jefferson scholarship. This article has been accepted for inclusion in Jefferson Journal of Psychiatry by an authorized administrator of the Jefferson Digital Commons. For more information, please contact: JeffersonDigitalCommons@jefferson.edu. 


\title{
The Other Drug War: Societal Attitudes and the Pharmacologic Treatment of Anxiety Disorders
}

\author{
Bruce Wenokur, D.O., M.P.H.
}

\begin{abstract}
Societal attitudes with respect to mood altering agents have undergone cyclical changes through American history. Cycles of relative tolerance and intolerance affect the perception of psychotropic drugs for illicit use, as well as legitimate medical therapy, often creating confusion between these two realms. This article examines the relationship between the prevailing social climate and the subsequent restrictions placed on the use of opiates. Historical attitudes toward opiate use serve as a model to explore the current social climate as it pertains to the pharmacologic treatment of anxiety. The undertreatment of anxiety disorders is hypothesized to result largely from social myths concerning both the nature and treatment of these conditions.
\end{abstract}

Social trends appear and disappear in cyclical fashion, waxing and waning like phases of the moon. Societal attitudes, fashions, and trends reflect the collective ideology and morality of the masses. It is often possible to generalize among many of these trends; hemline length may be as reflective of the social climate as attitudes toward psychoactive drugs. Unfortunately, because this climate does not discriminate, technologic achievements, including therapeutic advances in medicine, can fall victim to the collective societal psyche. This principle is evident in the field of clinical psychopharmacology. This article explores changes in pubic perception of psychoactive drugs in general and antianxiety agents in particular. The relationship between public perception of specific pharmacologic agents and the ability of physicians to use agents that alter behavior, treat somatic pain, and modulate symptoms of anxiety will be explored.

Societal attitudes with respect to mood altering drugs have undergone polar shifts throughout the history of America. In the nineteenth century, many of these substances, particularly the opiates and cocaine, were considered beneficial and used as tonics by all segments of society. Cocaine and morphine were easily available without prescription. The increasing awareness of the addictive potential of these drugs eventually caused a change in public acceptance of narcotics. This decreased tolerance of psychotropic agents began in the late nineteenth century and reached a peak in the early part of this century (1).

The introduction of the hypodermic needle in the mid-nineteenth century was quickly followed by legislation requiring a prescription to obtain narcotics. Public fear of these agents increased as did the numbers of narcotic-addicted individuals who 
used the intravenous route. Also, for the first time in American history, addiction became associated in the public mind with the health profession. Large segments of the population confused the legitimate use of these agents to treat pain with the careless use of these agents by the medical profession and also with illicit use not involving physicians. The cavalier attitude of many physicians with respect to narcotics certainly helped to create this perception. Eugene O'Neil dramatized his mother's physician-assisted addiction to morphine in his play, “A Long Day's Journey Into Night" (1).

A complex mixture of political conservatism, religious fundamentalism, and decreased social tolerance was pervasive in the United States during the latter part of the nineteenth and early twentieth century. This climate of increasing concern about mood-altering substances, including alcohol, contributed to the 1920's Prohibition. Additionally, as a result of increasing public intolerance toward mood-altering substances and the belief that the health profession was a major cause of addiction, the Harrison Narcotic Act was adopted in 1914 (1).

The Harrison Act required strict accounting of opium and coca importation into the United States, and rigid control of these substances for medical use was facilitated by a tax levied at each transfer point. Permits from the Treasury Department had to be obtained by pharmacists and physicians in order to dispense these agents. The Harrison Act as originally passed prohibited the maintenance of "addiction" except for specific medical purposes, such as pain resulting from cancer or tuberculosis (1).

A major effect of the Harrison Act was the virtual elimination of opiates for legitimate medical purposes. Treasury agents responsible for enforcement of the Harrison Act investigated and prosecuted many physicians who prescribed opiates with missionary-like zeal. Between 1915 and 1938, over 25,000 physicians were prosecuted under the Harrison Act (2).

During the 1920s and 1930s, the use of morphine and heroin declined markedly in this country (1). Unfortunately, no body of data exists to document the effects of narcotic restriction on patients with severe and chronic pain. It is easy to imagine the suffering of patients with terminal illnesses who were deprived of narcotic analgesics as a result of the Harrison Act.

The Harrison Act signified the height of psychoactive drug intolerance in this century. Prohibition was repealed in 1933, heralding a change in social attitudes. Following World War II and culminating in the decades of the 1960s and 1970s, a period of relative tolerance towards psychoactive drug use again reigned in this country (1). Experimentation with many mood-altering substances such as cannabis and hallucinogens became tacitly permitted in many segments of society (1).

In the $1980 \mathrm{~s}$ and continuing into the current decade, it appears that the pendulum of tolerance is again swinging toward blanket disapproval of any psychoactive drug use $(2,3,4)$. It is interesting to note that the current conservative social, moral, and political climate parallels that of the late nineteenth century and early twentieth century.

Additional fuel for the current heightened concern may stem from the very real 
problem of "crack" cocaine use. The use of this agent, one of the most physiologically rewarding substances known, has reached pandemic proportions $(5,6)$. The public is constantly barraged with evil associations to this drug, such as crack houses and widespread crime; and in the collective psyche, all "drugs" (mood-altering substances) may become similarly vilified.

When epidemiologic trends of drug abuse are studied, however, it is noted that consumption of many of the mood-altering substances such as alcohol, nicotine, cannabis, and cocaine powder have actually decreased in recent years $(5,6)$. Although use of many of these substances is on the wane, the "drug war" continues to escalate as if we are facing a narcotic Armagcddon. It is estimated that as much as $\$ 273$ billion a year is spent to wage this war, mostly related to the costs of arresting and imprisoning drug users (7). Only a very small proportion of this huge sum of money is spent on addiction research and substance abuse treatment.

Physicians are having an increasingly difficult time using mood-altering agents as part of medical treatment $(3,4,8)$. The health care professions are again viewed by society as part of the problem. This phenomenon is reflected in reactions to perceived misuse of psychotropics by physicians. Examples of these reactions may be found in legislative initiatives, such as triplicate prescription regulations. These sanctions create the vicious cycle of physicians unwilling to prescribe certain agents, which in turn causes a reluctance by needy patients to ask for them.

Paradoxically, the under-treatment of severe pain by physicians has recently been acknowledged by the Federal Government (9). The Food and Drug Administration issued a report in the spring of 1992 advocating a more judicious use of narcotics in the treatment of post operative pain and pain resulting from chronic and terminal conditions (9). The continued under-treatment of pain may be a vestige of the Harrison Act.

An additional component of the societal view of mood altering drugs may stem from the failure of the public and many physicians to distinguish between addiction and dependence. Dependence is a physiological phenomenon wherein the presence of a drug is required to maintain normal functioning. In the absence of the drug, withdrawal effects occur and the underlying disease process may reappear. Addiction is dependence coupled with a pathological need to obtain the drug at any cost (7). Addiction is a characterological phenomenon and often results in the drug-seeking and criminal behaviors that are stereotypical of the "addict."

Few people would consider diabetics to be addicted to insulin, although they are dependent upon this agent to maintain normal functioning. Studies have demonstrated that the vast majority of chronic pain patients using narcotics for long periods of time will be able to stop completely if the origin of their pain is eliminated (3). This is in marked contrast to the intravenous heroin addicts who take the drug solely for its euphoric effect and will commit crimes to obtain their next "fix."

The dynamics operating between society and health care providers and patients with respect to the use of psychotropic medications is difficult to delineate. It is evident that alternating cycles of tolerance and intolerance comprise the history of societal attitudes toward psychoactive substance use in this country. We will now turn 
our attention to the current social climate and its relationship to the pharmacologic treatment of anxiety disorders.

The experience of anxiety is a ubiquitous phenomenon of the human condition. From an evolutionary perspective, fear, anxiety, and even panic have considerable survival value. However, when anxiety or its physiologic manifestations becomes severe, unrelenting, and disabling, a person may be faced with a serious threat to his or her health and well being.

The concept of distinct anxiety "disorders" is continually changing. The clinical manifestations of anxiety may be described and categorized by many classification schemes. Panic disorder is one example of a distinct clinical anxiety syndrome. While the terminology and classification of anxiety disorders is quite fluid, the extent of human suffering resulting from these entities is easier to describe and quantify. Anxiety disorders are the most common psychiatric illnesses (11). Lifetime prevalence of all anxiety disorders, as determined by the Epidemiologic Catchment Area survey, ranges from 10.5 to 25 percent. Lifetime prevalence for panic disorder is consistently about 1.5 percent (12).

Research to determine the causes of anxiety disorders is taking place rapidly and involves many disciplines within psychology, psychiatry and the basic neurosciences. A significant body of knowledge now exists on the neurochemical, neuroanatomical, and psychodynamic determinants of anxiety disorders.

As a result of these varied research efforts, a similar leap has taken place in the therapeutic approaches to anxiety disorders. Specific pharmacologic agents that have anxiolytic activity have been available since the late $1950 \mathrm{~s}$. The tricyclic and monoamine oxidase inhibitor antidepressants and the benzodiazepines are all considered safe and effective pharmacologic treatments for anxiety disorders (13).

Similar advances have taken place in psychodynamic psychotherapies as well as cognitive and behavioral approaches to anxiety disorders. Current state-of-the-art treatment of anxiety disorders usually involves pharmacotherapy in combination with some form of psychotherapy and possibly adjunctive behavioral or cognitive techniques (13). However, current estimates suggest that only one-quarter of anxiety disorder patients receive any form of treatment for their distress (11).

Anxiolytic medications, particularly benzodiazepines, are a primary modality in the clinical management of severe anxiety disorders, yet recent data indicates that these agents, like the opiates, are considerably under-utilized in clinical practice $(14,15)$. It is to this issue which we will now shift the focus.

Epidemiologic data from the United States Household Survey on the use of Psychotherapeutic Medication reveals that between 1979 and 1990, a significant decline occurred in the use of anxiolytic medications, especially benzodiazepines (14). This decline occurred despite unchanged prevalence rates for anxiety disorders. It is clear from the data that this decline in usage came at the expense of individuals with clinically significant anxiety disorders. Furthermore, there has not been a shift to the use of alternative medications or non-pharmacologic therapies during this time period.

Benzodiazepines have been demonstrated to be safe and effective agents for the 
treatment of both acute and chronic anxiety disorders (15). Despite the significant decline in benzodiazepine prescriptions and availability in the last decade, reservations about their continued use persist among physicians and the general public (15). The data from several large cross-sectional studies of benzodiazepine use reveal that fears about the overuse and abuse of these agents is greatly exaggerated (15). Furthermore, these fears may create a climate that may deprive patients of appropriate therapy.

Approximately 11 percent of Americans (14 percent of women and 8 percent of men) have used a benzodiazepine during the previous year (15). These data reflect all benzodiazepine use, including hypnotics for sleep disorders. By comparison, the overall one-year prevalence for benzodiazepine use in other Western countries ranges from a high in Belgium of 17.6 percent to a low of 7.4 percent in the Netherlands. Only 1.7 percent of the survey population in the U.S. used benzodiazepines daily for a 12-month period. Two-thirds of the sample population used them daily for less than one month's duration (15). Long-term users were much more likely than short-term users to be older, have higher levels of psychic distress (using standardized symptom checklists for anxiety), and have more somatic symptoms. Furthermore, many "medical" problems were chronic and severe, such as cardiovascular and rheumatologic conditions. "Chronic" users of benzodiazepines are thus likely to be appropriate candidates for the use of these agents (15).

Benzodiazepine dependence is strikingly low, given the large patient populations who are exposed to these agents (15). Contrary to popular belief, there are fewer patients abusing benzodiazepines than would be expected from the relative availability of these agents. Most patients taking a benzodiazepine for anxiety disorder symptoms do not show any symptoms of addiction or abuse, and in fact, the reverse is true. Long-term users of benzodiazepines usually take their medication on an as-needed basis. There is no evidence that chronic users exhibit continued dose escalation. Most long-term users, in fact, usually attempt to seek the lowest effective dose to relieve symptoms $(15,16)$.

Other indicators of abuse, such as recreational use, visits to multiple physicians seeking the same drug, the overwhelming need to use the drug, or significant functional impairment are virtually nonexistent with benzodiazepine users. One study profiled hospitalized benzodiazepine abusers, revealing that of 1,347 patients admitted with a substance abuse disorder, 136 patients had a primary or secondary diagnosis of benzodiazepine abuse (17). Benzodiazepine abusers were likely to have a secondary Axis I diagnosis (45 percent), with depression most common (18 percent), followed by adjustment disorder (14 percent), somatoform disorder ( 5 percent), and bipolar disorder (4 percent). Only 6 percent of benzodiazepine abusers misused these agents exclusively (17).

The myths and misperceptions regarding the dangers of benzodiazepines are easily understood in view of the changing popular attitudes and beliefs towards tranquilizers in our society. The results of large household surveys conducted in 1970 and again in 1979 reveal several striking trends: although no change in the perceived efficacy of these agents occurred in the study decade, the general belief that these 
agents are unwarranted and over-prescribed became more common. In 1970, 61 percent of nonuser respondents believed that doctors over-prescribed tranquilizers. This figure increased dramatically in 1979 to 83 percent (4).

More people (62 percent) in 1979 agreed with the statement, "Using tranquilizers just prevents people from working out their problems for themselves," than in 1970 (57 percent). More than 80 percent agreed with the statement, "It is better to use willpower to solve problems than it is to use tranquilizers." This figure remained relatively constant. Interestingly, 72 percent of nonuser respondents in 1970 and 1979 agreed with the statement, "Tranquilizers work very well to make a person calm and relaxed." In this same study 60 percent of respondents were unwilling to condone tranquilizer use when severe anxiety symptoms result in a loss of job functioning or disruption of family life (4).

The results of these surveys suggest that a large segment of the population views anxiety disorders as deficits in character rather than disease processes. Paradoxically, although a majority of the population believes that anxiolytic medications work well to alleviate anxiety symptoms, they are not willing to condone their use even in situations of significant impairment.

More recent data reveal that these trends continue, and in fact attitudes toward the use of benzodiazepines may have become more rigid (11). Prevalence rates for benzodiazepine use continue to decline. Many patients whose symptoms merit pharmacologic treatment simply are not receiving these agents (11). Equally disturbing is the possibility that many patients who have benefitted from these agents in the past may no longer have access to them and are receiving neither alternative medication nor non-pharmacologic treatment.

Legislative efforts to limit and control the prescription of certain psychotropics are a result of public attitudes about perceived dangers of these substances. The impact of regulatory efforts on physician prescribing practices can be studied, and provides an indirect gauge of societal attitudes that effect the medical profession.

In January of 1989, the state of New York issued regulations requiring the use of triplicate prescription procedures for the clinical use of benzodiazepines (8). Triplicate prescriptions are required in many states for dispensing Schedule II drugs (high abuse potential). With the New York legislation, benzodiazepines became the only Schedule IV medication (low potential for abuse) to require such procedures (4). Contrary to existing data, the New York State Department of Health stated that benzodiazepines are a major public health problem and cited this as the major reason for the decision (4).

A recently published study has reviewed the consequences of the triplicate prescription regulations in New York (8). From 1988 to 1989, prescriptions for benzodiazepines decreased by 44 percent. However, this decline was accompanied by a marked increase in the use of less effective and more dangerous substitutes. For example meprobamate use increased by 125 percent in New York as compared to a decrease in nation-wide use ( -9 percent) during the study year. Butibarbital prescriptions increased by 31 percent versus -15 percent nationally (8). Both of these agents have a high abuse potential coupled with an increased risk of fatal overdose. 
The authors of this study conclude that mandated triplicate prescriptions of benzodiazepines may result in undertreatment of clinically significant anxiety. Furthermore, many patients with anxiety disorders may receive inappropriate, ineffective, and possibly dangerous alternatives (8).

It is clear that societal attitudes can have a serious negative impact on clinical practices, especially in the realm of psychotropic medications. The implications of this adverse relationship are staggering. The personal distress resulting from undertreatment of pain and anxiety is apparent. The secondary effects of this situation such as lost productivity, divorce, and suicide rates are harder to study and quantify. It is distressing to think that these attitudes and misperceptions may actually hinder the development of new and safer psychotropics. The consequences of intolerance are felt at all levels of society, including in the institutions and among scientists conducting pharmacologic research.

We have seen that societal misperceptions about the psychotropic effects of analgesic and anxiolytic medications have resulted in undertreatment of pain of many types and the particular psychic pain related to overwhelming anxiety. The relationship of societal attitudes to the use of psychotropic agents is a subset of the larger problem of the historical stigmatization of mental illness. This stigmatization continues unabated as we approach the twenty-first century. Although we no longer burn the insane at the stake, misperceptions about the causes and treatment of mental illness continue to be rampant. Misinformation and ignorance with respect to the nature of psychiatric illness and the efficacy of somatic treatments for these conditions will continue to result in needless suffering.

Physicians can help to dispel these myths at all levels of society. This can only happen when the medical profession itself is ready and willing to de-stigmatize mental illness. This process must begin early during medical education. Only by increasing awareness can we hope to end "the other drug war" and use effective medications unhindered and without fear.

\section{ACKNOWLEDGMENT}

The author would like to thank Linn Campbell, M.D., and Harvey Rosen, M.D. for their thoughtful review of this article and Dawn Worley for her assistance with the preparation of the manuscript.

\section{REFERENCES}

1. Musto D: Opium, cocaine and marijuana in American history. Scientific American 1991; July:40-47

2. Hoffman JP: The historical shift in the perception of opiates: from medicine to social menace. Journal of Psychoactive Drugs 1991; 22:53-62

3. Morgan JP: American opiophobia: customary underutilization of opioid analgesics, in Advances in Pain Research and Therapy, by CS Hill and WS Fields (editors). Raven Press, New York, 1989 
4. Clinthorne JK, Cisin IH, Balter M, et al: Changes in popular attitudes and beliefs about tranquilizers. Archives of General Psychiatry 1986; 43:527-532

5. U.S. Department of Health and Human Services: National Household Survey on Drug Abuse: Main findings 1985, DHHS Publication No. (ADM) 88-1566, Washington, D.C., 1988

6. U.S. Department of Health and Human Services: National Household Survey on Drug Abuse: Population Estimates 1990., DHHS Publication No. (ADM) 91-1732, Washington, D.C., 1991

7. Rice DP, Kelman S, and Miller LS: Estimates of economic costs of alcohol and drug abuse and mental illness, 1985 and 1988, Public Health Reports 1991; 106:280-292

8. Weintraub M, Singh S, Byrne L, et al: Consequences of the 1989 New York state triplicate benzodiazepine prescription regulations. Journal of the American Medical Association 1991; 266:2392-2397

9. Sullivan LW (Secretary of Health and Human Services): Press release, Pain Management Guidelines, Federal Food and Drug Administration, March 5, 1992

10. Jaffe JH: Misinformation: Euphoria and addiction, in Advances in pain Research and Therapy, by CS Hill and WS Fields (editors). Raven Press, New York, 1989

11. Weissman MM: The epidemiology of anxiety disorders: rates, risks and familial patterns. Journal of Psychiatric Research 1988; 22(1S):99-114

12. Robins LN, Helzer JE, Weissman MM: Lifetime prevalence of specific psychiatric disorders in three sites. Archives of General Psychiatry 1984; 41:949-958

13. Kaplan H, Freeman A, Sadock B: Comprehensive Textbook of Psychiatry, Fifth Edition. Williams and Wilkins, Baltimore 1989

14. Balter MB, Uhlenhuth EH: Prescribing and use of benzodiazepines: an epidemiologic perspective. Journal of Psychoactive Drugs 1992; 24:63-64

15. Uhlenhuth EH, DeWitt J: Risks and benefits of long term benzodiazepine use. Journal of Clinical Psychopharmacology 1988; 8:161-167

16. Romach MK, Busto UE, Sobell LC, et al: Long term alprazolam use: abuse, dependence or treatment? Psychopharmacology Bulletin 1991; 27:391-395

17. Brady KT, Johnson AL, Cunningham M, et al: Profiles of hospitalized benzodiazepine abusers. Journal of Psychoactive Drugs 1991; 23:71-72 